\title{
Causative Organisms of Cellulitis - A Retrospective Study
}

\author{
Vedha Pal Jeyamani S1,*, Asha K Rajan'1, Indumathi S1, Divya R', Lavanya R'1, Prema M', Narendra Babu² \\ 'Department of Pharmacy Practice, Jaya College of Paramedical Sciences, Chennai, Tamil Nadu, INDIA. \\ ${ }^{2}$ Assistant Surgeon, Govt Head Quarters Hospital, Thiruvallur, Chennai, Tamil Nadu, INDIA.
}

\begin{abstract}
Background: Cellulitis, especially of the lower limbs is found to be more common now-a-days in both the sexes. Ascending cellulitis was found to pose both short and long term morbidities. Objective and Methodology: The following study carried out is at the general medicine ward of a government hospital where about 90 patients were taken for study with their cellulitis condition. Demographic details and their predisposing causes towards the condition were noted and risk factors were identified. Results: Diabetes, infections due to streptococci, infections from tinea pedis etc, were the main etiological conditions among others contributing to increased cellulitis cases. Risk factors in both ipsilateral and contralateral limbs were recorded and studied upon. Long term morbidity of most of the patients was identified for which a proper follow-up along with serological examination for critical diagnosis could be carried out. Culturing of the wound for identifying the causative organism is a prior issue which would
\end{abstract}

reduce the risk of antibiotic resistance. Prophylaxis with Penicillins and its derviatives, both natural and synthetic could be suggested for long term conditions and avoiding recurrent episodes. Common therapy was with Cephalosporin (23), Ciprofloxacin (29) etc. both natural and synthetic penicillins were also found to be given in a good number. Key words: Cellulitis, Limbs, Penicillins, Streptococci, Morbidity.

Correspondence

Prof S. Vedha Pal Jeyamani, Professor, Department of Pharmacy Practice, Jaya College of Paramedical Sciences, Chennai, Tamil Nadu, INDIA.

Phone: 044-25931362

Email: swetha21112000@gmail.com

DOI: 10.5530/jyp.2018.10.81

\section{INTRODUCTION}

Among Cellulitis of various regions, ascending cellulitis of the leg was a common medical emergency characterized by edema, fever, swelling and malaise. It is one among the multidisciplinary disorder. ${ }^{1-3}$ Common organisms leading to higher frequency of cellulitis include Streptococci, mixed infections in particular when cellulitis is localized or a penetrating injury. ${ }^{4-6}$ Most of the time bacteriological diagnosis is difficult due to no wound site present for culturing. Severity of streptococcal infections include streptococcal toxic shock syndrome, necrotizing fasciitis, other conditions which may progress due to poor therapy include infected venous eczema or lymphoedema, deep venous thrombosis, myositis or fasciitis, tibial compartment syndrome etc. ${ }^{7-11}$

Cellulitis is the inflammation of the skin and soft tissue caused due to bacterial infections majorly affecting the lower limbs. It is sometimes also called as Lymphangitis or Erysipelas. ${ }^{12-15}$ Associated risk factors for cellulitis include lymphoedema/ chronic edema, Diabetes, primary or secondary insect bites, blistering disorders like bullous pemphigoid, skin trauma/ ulcers, animal bites, bullous impetigo, skin rash-eczema, dry skin, obesity, kidney and liver disease etc. ${ }^{16-19}$

Initial appearance of the skin is generally glossy, tight, stretched. Tenderness and pain of the affected area is seen. Occassionally, swelling of the local lymph nodes is observed with other common symptoms like fever accompanied with or without chills, fatigue, sweating, muscle pains, malaise. ${ }^{20-24}$ Diagnosis made involve culture studies, blood test, imaging studies etc. Treatment carried out involved antibiotics, with steroids occasionally.

Some of the cases monitored were as below.

\section{PROCEDURES AND METHODS}

The study was carried out at the general medicine ward of Thiruvallur Government Hospital for a period of 3 months. A written consent was collected from all the patients who were included in the study. A close observation was done on cases of cellulitis and patients were selected based upon the following criteria. Inclusion criteria were those with predisposing conditions of cellulitis like diabetes, skin disorders, local injury etc. those who were willing to reveal their consent were selected. Exclusion criteria were localized cellulitis, bursitis or abscesses cases or those made with incorrect diagnosis (Figure 1,2,3).

About 90 patients were chosen for the study based on the criteria's and data obtained were on demographic details, short-term morbidity, predisposing cause, antibiotic therapy, duration of admission, diagnosis, therapy after discharge. Previous episodes of attacks were documented in addition to any long term morbidity found in the patients.

\section{RESULTS AND DISCUSSION}

Out of the 90 patients ( 48 females and 42 males) with age of 50-75 years (median age $62.5 \pm 3.5$ years), most of them were observed with pyrexia, malaise, edema etc, at the time of admission. About some 25 patients were found to be apyrexial along with cellulitis. Among the various preceding causesfoundincellulitis patients, thosewith infection dueto Tinea pedis (13/90), a minor non-penetrating local injury (10/90) were found to be common (Table 1). Others had eczema of foot (9/90), diabetic foot ulcer $(5 / 90)$ in which the condition worsen from the foot towards the upper knee. Leg ulceration (7/90) was also found to be common. Common concomitant diseases accompanied with the patients were cardiovascular diseases (45/90) while all others were found to be less in number (Table 4).

From the total number of patients selected for the study only about $38 \%$ (42 patients) had their wounds taken for culture examination. Among the performed culture test of the patient's dermatophytes (55\%), Staphylococcus aureus (38\%) were more common (Figure 5). Single culture could also identify the presence of more than one organism where again dermatophytes and Staphylococcus aureus were common. ${ }^{25-29}$

Risk factors persisting in the patients were with recurrent episodes of cellulitis (25/90). They had an episodal attack of 1 to 2 times which were

This is an open access article distributed under the terms of the Creative Commons Attribution-NonCommercial-ShareAlike 4.0 License, which allows others to remix, tweak, and build upon the work non-commercially, as long as the author is credited and the new creations are licensed under the identical terms. 


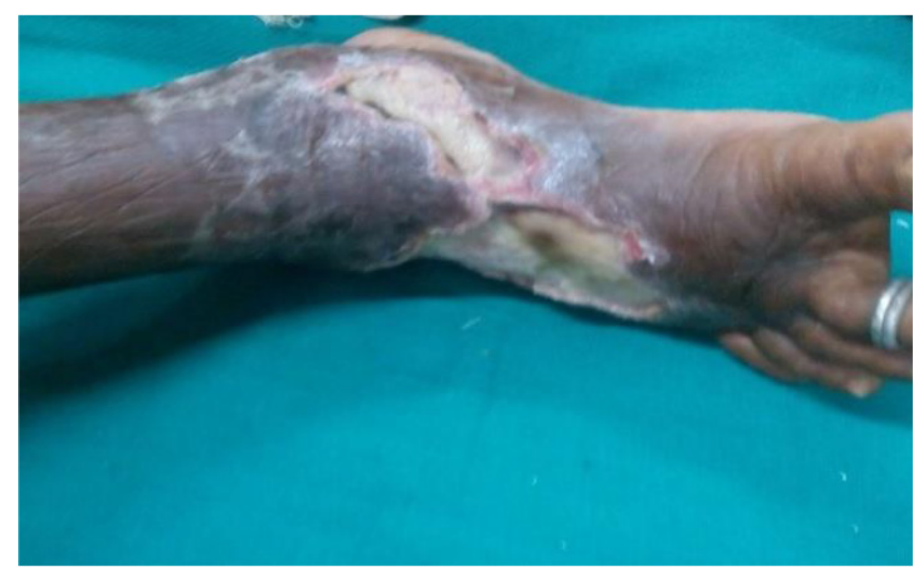

Figure 1: Cellulitis in right leg with plagues.

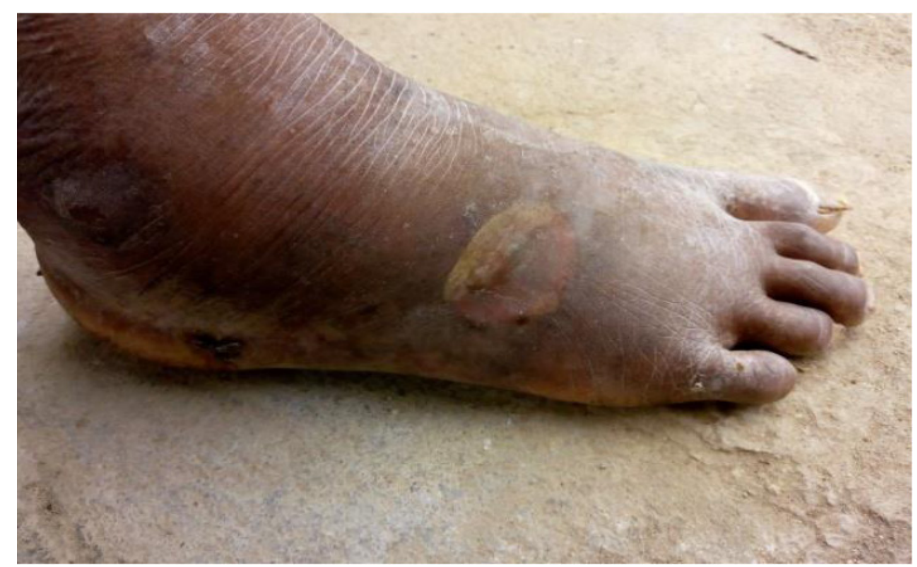

Figure 2: Cellulitis in leg with edematous plagues.

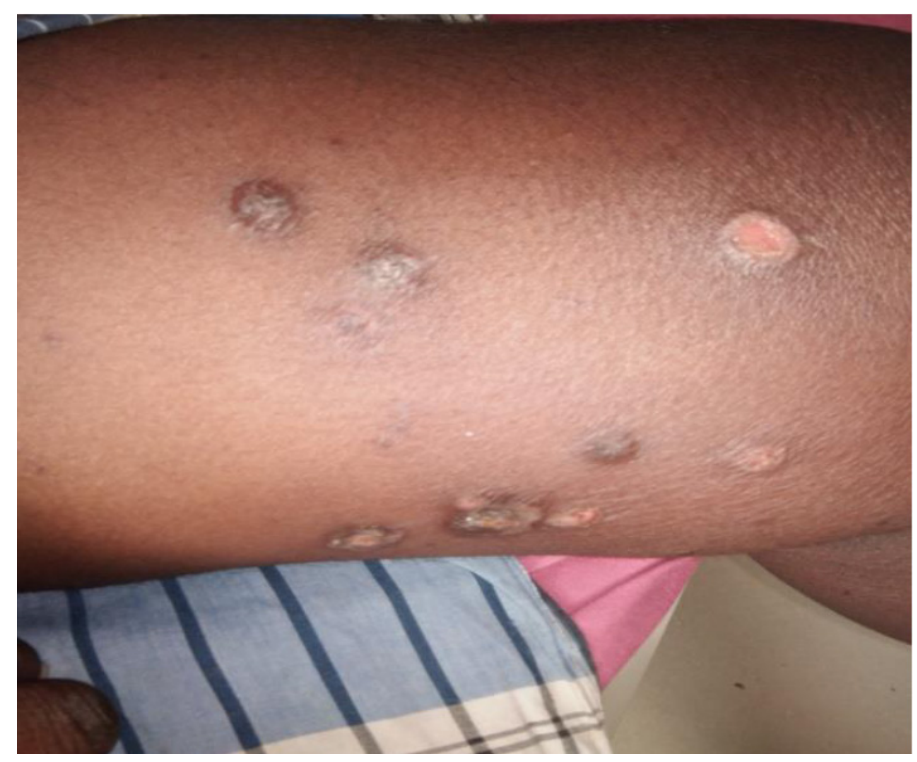

Figure 3: Cellulitis with skin eruptions in Right thigh.
Table 1: Preceding causes of cellulitis in the patients were as follows.

\begin{tabular}{ccc}
\hline Portals & No: of patients & $\%$ of patients \\
\hline Leg ulceration & 7 & $7.7 \%$ \\
Diabetic foot ulcer & 5 & $5.5 \%$ \\
Blisters of foot & 2 & $2.2 \%$ \\
Severe lymphoedema & 1 & $1.1 \%$ \\
Local injury (minor, non-penetrating) & 10 & $11.1 \%$ \\
Eczema of foot/ leg & 9 & $10 \%$ \\
Tineapedis/ toe web maceration & 13 & $14.4 \%$ \\
\hline
\end{tabular}

Table 2: Demographic details of patients.

\begin{tabular}{cc}
\hline Factors & Case patients $(\mathbf{n}=\mathbf{9 0})$ \\
\hline Median age & $62.5 \pm 3.5 \mathrm{yrs}$ \\
Sex: & \\
Male & 42 \\
Female & 48 \\
Concomitant diseases of patients: & \\
Gastrointestinal & $9(10 \%)$ \\
Psychiatric & $8(8.8 \%)$ \\
Pulmonary & $10(11.1 \%)$ \\
Cardiovascular & $45(50 \%)$ \\
Others & $18(20 \%)$ \\
\hline
\end{tabular}

Table 3: Commonly found microorganism causing cellulitis in the patients.

\begin{tabular}{|c|c|c|c|}
\hline Microorganism & $\begin{array}{l}\text { Commonly } \\
\text { occurring body } \\
\text { site }\end{array}$ & $\begin{array}{l}\text { No of patients } \\
\text { affected by the } \\
\text { organism }\end{array}$ & $\%$ of patients \\
\hline $\begin{array}{l}\text { Staphylococcus } \\
\text { aureus (found with } \\
\text { other organisms } \\
\text { too in same } \\
\text { individual) }\end{array}$ & $\begin{array}{l}\text { Usually } \\
\text { occurring in any } \\
\text { parts of the body }\end{array}$ & 38 & $42.2 \%$ \\
\hline $\begin{array}{c}\beta \text {-hemolytic } \\
\text { streptococci (group } \\
\mathrm{A}, \mathrm{B}, \mathrm{C}, \mathrm{G} \text { ) }\end{array}$ & $\begin{array}{l}\text { Parts of the foot } \\
\text { and inner thighs }\end{array}$ & 36 & $40 \%$ \\
\hline $\begin{array}{l}\text { Dermatophytes } \\
\text { (found with other } \\
\text { organisms too in } \\
\text { same individual) }\end{array}$ & $\begin{array}{c}\text { Foot, toe webs, } \\
\text { toe nails, sole } \\
\text { of foot }\end{array}$ & 55 & $61.1 \%$ \\
\hline $\begin{array}{c}\text { Gram negative } \\
\text { bacilli }\end{array}$ & Toe webs & 18 & $20 \%$ \\
\hline
\end{tabular}

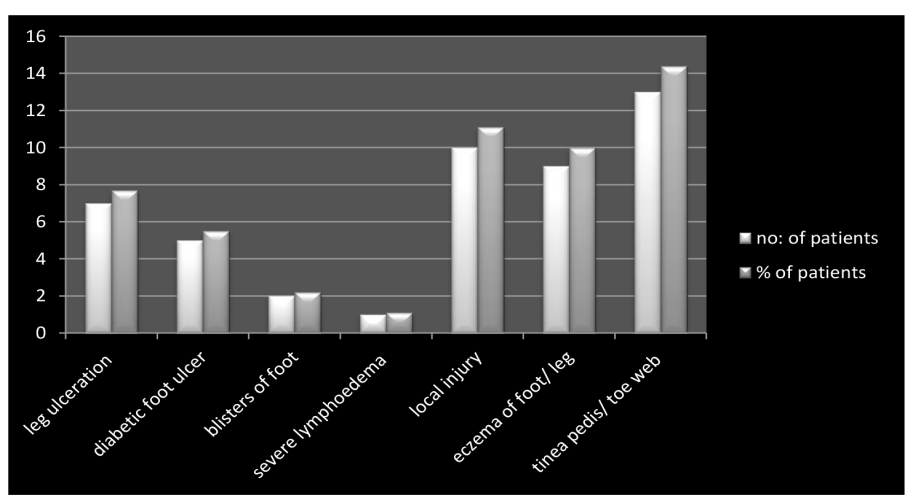

Figure 4: Predisposing causes of cellulitis in pictorial representation. 


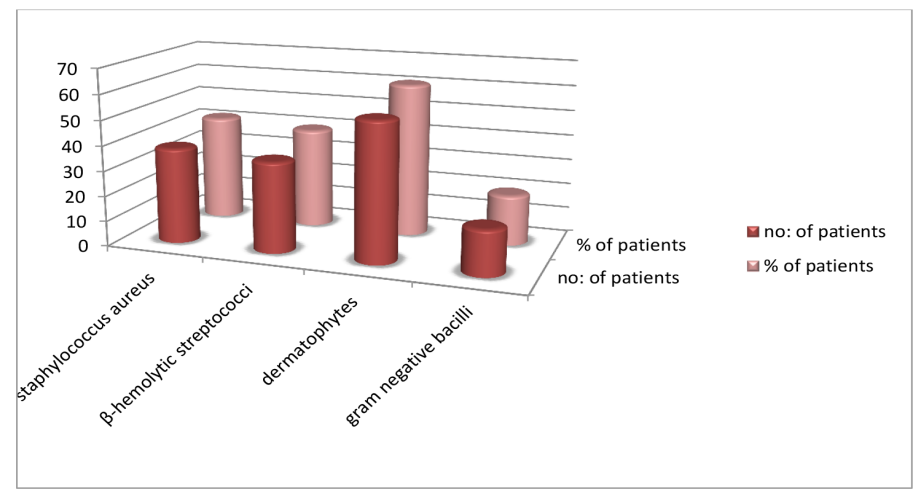

Figure 5: Analysis of Causative organisms causing cellulitis.

Table 4: Risk factors associated with cellulitis in the patients group.

\begin{tabular}{|c|c|c|}
\hline Factors & No: of patients & $\%$ of patients \\
\hline Obesity (BMI $\geq 30)$ & 5 & $5.5 \%$ \\
\hline $\mathrm{BMI}>25$ and $<30$ & 25 & $27.7 \%$ \\
\hline Diabetes mellitus & 11 & $12.2 \%$ \\
\hline Smoking & 15 & $16.6 \%$ \\
\hline Skin disease & 22 & $24.4 \%$ \\
\hline \multicolumn{3}{|c|}{ Persisting history of the following conditions } \\
\hline Cellulitis with & & \\
\hline - Leg ulcer & 25 & $27.7 \%$ \\
\hline - Chronic leg edema & 10 & $11.1 \%$ \\
\hline - Leg lesions & 3 & $3.3 \%$ \\
\hline - Dry skin & 8 & $8.8 \%$ \\
\hline - Dermatophytes & 4 & $4.4 \%$ \\
\hline - Bacterial microorganisms & 20 & $22.2 \%$ \\
\hline $\begin{array}{l}\text { ( } S \text {, aureus and } \beta \text { Hemolytic } \\
\text { streptococci) in foot and toe }\end{array}$ & 30 & $33.3 \%$ \\
\hline - Dermatitis & 12 & $13.3 \%$ \\
\hline - Varicose veins & 18 & $20 \%$ \\
\hline - Toe nail dystrophy & 52 & $57.7 \%$ \\
\hline - Abnormalities of sole & 45 & $50 \%$ \\
\hline
\end{tabular}

Table 5: Details on Risk factors associated with the sides of the limbs in the patients.

\begin{tabular}{cccc}
\hline $\begin{array}{c}\text { Risk factors of the } \\
\text { patients }\end{array}$ & $\begin{array}{c}\text { Found in } \\
\text { Ipsilateral } \\
\text { limbs }\end{array}$ & $\begin{array}{c}\text { Found in } \\
\text { Contralateral } \\
\text { limbs }\end{array}$ & $\begin{array}{c}\text { Found } \\
\text { in both } \\
\text { limbs }\end{array}$ \\
\hline $\begin{array}{c}\text { History of patients: } \\
\text { Leg ulcer }\end{array}$ & 7 & 1 & 3 \\
Chronic leg edema & 5 & 0 & 20 \\
Cellulitis & 33 & 4 & 2 \\
Leg surgery & 8 & 0 & 3 \\
Current conditions along & & & \\
with cellulitis & & & \\
Statis dermatitis & 5 & 3 & 3 \\
Varicose veins & 4 & 0 & 10 \\
Dry skin & 6 & 2 & 20 \\
Leg lesion & 10 & 1 & 5 \\
Abnormalities of the sole & 7 & & 23 \\
\hline
\end{tabular}

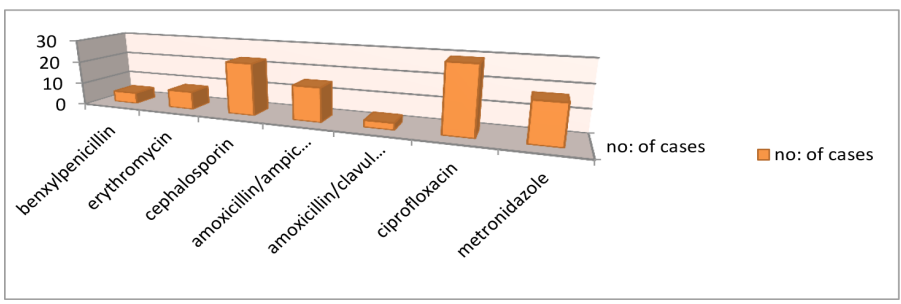

Figure 6: Antibiotic therapy observed on the patients.

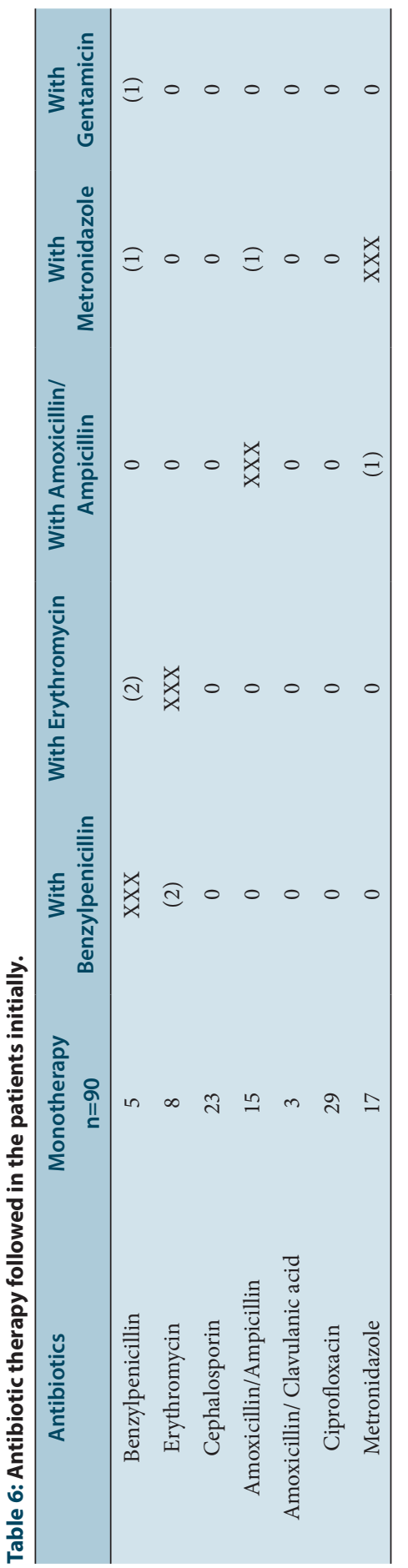


unpreventable due to antibiotic resistance in them. ${ }^{30-33}$ Resistance towards microorganisms like staphylococcus aureus and $\beta$-hemolytic streptococci (30/90) initiating from the foot or toe and their rising upwards were also a risk factor towards ascending limb cellulitis.

Dermatophytes (20/90) and leg ulcer (30/90) were also prominent etiological and risk factor in most of the patients examined upon. ${ }^{34,29}$ Lesions and dry skin due to excessive sunlight exposure and other conditions were found to be common. Diabetes, smoking, abnormalities of the sole, toenail dystrophy etc, were the other factors found towards contributing to present condition. Skin and vascular abnormalities condition like statis dermatitis (12), dry skin (6), varicose vein (18) etc, were also found in a good number as contributing conditions.

Common therapy was with Cephalosporin (23), Ciprofloxacin (29) etc. both natural and synthetic penicillins were also found to be given in a good number. Those allergic with Benzylpenicillin were preferred with erythromycins. Long term morbidities or frequent conditions could be treated with Benzylpenicillin based on literature studies. ${ }^{35-36}$

\section{CONCLUSION}

From the study it could be concluded that the main contributing etiological conditions towards cellulitis were streptococci, lymphoedema, infection due to tinea pedis, etc, which all when left untreated could lead to repeated episodes of cellulitis and morbidity of it. Benzylpenicillin and other penicillins would be suggested for long term use or prophylaxis for cellulitis due to its improving results when compared to other drugs. Culture examination and prescribing of required narrow line antibiotics would lay down to decreased resistance towards antibiotics unnecessarily.

\section{ACKNOWLEDGEMENT}

The authors are thankful to the patients who have given consent for the present study and made this work successful

\section{CONFLICT OF INTEREST}

The authors declare no conflicts of interest concerning the content of this case report.

\section{ABBREVIATIONS}

BMI: Body mass index; S. aureus: Staphylococcus aureus.

\section{SUMMARY}

The study carried out upon cellulitis patients highlights the etiological causes, main causative organisms and therapy followed in them. Penicillin was found to be a good antibiotic for cellulitis patients, which even prevents recurrent attacks of cellulitis. Ascending cellulitis of the limbs was found to be in common, where diabetes condition was a prior etiological factor for most of the cases. Pharmacists role mainly involved in culturing of the wound section which is in most cases neglected, being a common factor for antibiotic resistance. Other points could be in counseling of the patients and making them take the precaution steps in advance.

\section{REFERENCES}

1. Leppard BJ, Seal DV, Colman G, Hallas G. The value of bacteriology and serology in the diagnosis of cellulitis and erysipelas. Br J Dermatol. 1985;112(5):559-67.

2. Sachs MK. Cutaneous cellulitis. Arch Dermatol. 1991;127(4):493-6.

3. Bernard P, Bedane C, Mounier M, et al. Streptococcal cause of erysipeals and cellulitis in adults. A microbiologic study using a direct immunofluorescence tenchnique. Arch Dermatol. 1989;125(6):779-82.

4. Hook EW, Hooton TM, Horton CA, et al. Microbiological evaluations of cutaneous cellulitis in adults. Arch Intern Med 1986:146(2):295-7.
5. Lebre C, Girard-Pipau F, Roujeau JC, Revuz J. Value of fine needle aspiration in infectious cellulitis. Arch Dermatol. 1996;132(7):842-3

6. Epperley TD. The value of needle aspiration in the management of cellulitis. J Fam Pract. 1986;23(12):337-40.

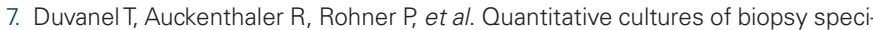
mens from cutaneous cellulitis. Arch Intern Med. 1989;149(2):293-6.

8. Pierce RP, Daugird AJ. Recurrent leg cellulitis: Pathogenesis, prevention and treatment. J Am Board Fam Pract. 1992;5(1):85-7.

9. Nohlgard C, Bjorklind A, Hammar H. Group G streptococcol infections on a dermatological ward. Acta Dermatovenercol. 1992;72(2):128-30.

10. Baddour LM, Bisno AL. Non-group a beta-hemolytic streptococcal cellulitis: Association with venous and lymphatic compromise. Am J Med. 1985;79(2): 155-9.

11. Drinker CK, Field ME, Ward HK, et al. Increased susceptibility to local infection following blockage of lymphatic drainage. Am J Physiol. 1983;112(1):74-81.

12. Edwards EA. Recurrent febrile episodes and lymphoedema. JAMA. 1963;184(11):858-62.

13. Brodell JD, Brodell RT. Recurrent lympahantigic cellulitis syndrome. Contemp Orthop. 1992;25:461-8.

14. Pauszek ME. Prophylaxis for recurrent cellulitis complicating venous and lymphatic insufficiency. Indiana Med. 1991;84(4):252-3.

15. Dupuy A, Benchikhi $H$, Roujeau JC, Bernard $P$, Vaillant $L$, chosidow $O$, et al. Risk factors for erysipelas of the leg (cellulitis): Case-control study. BMJ. 1999;318(7198):1591-4

16. Mallon E, Powell S, Mortimer P, Ryan TJ. Evidence for altered cells-mediated immunity in postmastectomylymphoedema. Br J Dermatol. 1997; 134:928-933.

17. Kerchner K, Fleischer A, Yosipovitch G. Lower extremity lymph edema update: Pathophysiology, diagnosis, and treatment guidelines. J Am Acad Dermatol. 2008;59(2):324-31.

18. Fang J, Dagenasis SL, Erickson RP, Arlt MF Glynn MW, Gorski JL, et al. Mutations in FOXC2 (MFH-1), a fork head family transcription factoer are responsible for the hereditary lymphedeme-distichiasis syndrome. Am J Hum Genet. 2000;67(6):1382-8.

19. Murray P, Rosenthal K, Pfaller M. From Wucheriabancrofiti and Brugiamalayi. In Medical Microbiology $5^{\text {th }}$ edition. Philadelphia: Elsevier Mosby. 2005:888-890.

20. Kasai-Sakamoto A, Yokoyama Y, Mizunuma $\mathrm{H}$ : A case of cellulitis that complicated lymphedema of the lower limb and produced systemic inflammatory response syndrome (SIRS). Eur J Gynaecol Oncol. 2006;27(4):419-21.

21. Kilburn SA, Featherstone $P$, Higgins $B$, Birndle R. Interventions for cellulitis amderysipeals, Cochranae Database of systematic Reviews. 2010; 6.

22. Leman P, Mukherjee D. Flucloxacillin alone or combined with benzylpenicillin to treat lower limb cellulitis: A randomised controlled trial. Emergency Medicine Journal. 2005:22(5):342-6.

23. Mortimer P. Acute inflammatory episodes. In TwycrossR, Jennes $\mathrm{K}$ and Todd J, (Eds), Lympho edema. 2000.

24. Perl B, et al. Cost-effectiveness of blood cultures for adult patients eith cellulitis. Clin Infect Dis. 1999;29(6):1483-8.

25. Bailey $E$, et al. Cellulitis: Diagnosis and management. Dermatol Ther 2011;24(2):229-39.

26. Spellberg $B$, et al. Antimicrobial agents for complicated skin and skin structure infections: justification of non-inferiority margins in the absence of placebocontrolled trials. Clin Infect Dis. 2009;49(3):383-91.

27. Carratala $\mathrm{J}$, et al. Factors associated with complications and mortality in adult patients hospitalized for infectious cellulitis. Eur J ClinMicrobiol Infect Dis. 2003;22(3):151-7.

28. Jorup-Ronstrom $C$, et al. Recurrent erysipelas: Presdisposing factors and costs of prophylaxis. Infection. 1987;15(2):105-6.

29. Sabishruthi S, Vedha pal Jeyamani S, Punitha S, Kavitha S, Franklin Jose J. Acute eczema with cellulitis and eruption on both legs - Case study. International Journal of Pharmacy and Pharmaceutical Research. 2017;10(4):243-7.

30. Lamagni $\mathrm{TL}$, et al. Epidermiology of severe Streptococcus pyogenes diseases in Europe. J Clin Microbial. 2008;46(7):2359-67.

31. Carratala J, Roson B, Fernandez-Sabe N, et al. Factors associated with complications and mortality in adult patients hospitalized for infectious cellulitis European journal of clinical Microbiology Infectious Disease. 2003:22(3):151-7.

32. Dupuy A, Benchikhi $H$, Roujeau JC, et al. Risk factors for erysipelas of the leg (cellulitis): case-control study. BMJ. 1999;318(7198):1591-4.

33. Simosen $\mathrm{SE}$, et al. Cellulitis incidence in a defined population. Epidermiol Infect. 2006;134(2):293-9.

34. Semel JD, Goldin H. Association of the athelete's foot with cellulitis of the lower extremities: diagnostic value of bacterial cultures of ipsilateral space samples. Clinical Infectious Disease. 1996;23(5):1162-4

35. Leyden JJ, Kligman AM. Interdigital athelete's foot: The interaction of dermatophytes and resident bacteria. Arch Dermatol. 1978;114(10):1466-72.

36. Hook EW, Hooton TM, Horton CA, Coyle MB, Ramsey PG, Turck M. Microbiologic evaluation of cutaneous cellulitis in adults. Arch Intern Med. 1986;146(2):295-7. 